\title{
Synergistic Enhancement of Paclitaxel-Induced Inhibition of Cell Growth by Metformin in Melanoma Cells
}

 \\ ${ }^{1}$ Dept. of Medicine, Jeju National University School of Medicine, Jeju 63243, Korea \\ ${ }^{2}$ Histology, Jeju National University School of Medicine, Jeju 63243, Korea
}

\begin{abstract}
Melanoma is one of the most aggressive and treatment-resistant malignancies. Antidiabetic drug metformin has been reported to inhibit cell proliferation and metastasis in many cancers, including melanoma. Metformin suppresses the mammalian target of rapamycin (mTOR) and our previous study showed that it also inhibits the activity of extracellular signal-regulated kinase (ERK). Paclitaxel is currently prescribed for treatment of melanoma. However, paclitaxel induced the activation of ERK/mitogen-activated protein kinase (MAPK) pathway, a cell signaling pathway implicated in cell survival and proliferation. Therefore, we reasoned that combined treatment of paclitaxel with metformin could be more effective in the suppression of cell proliferation than treatment of paclitaxel alone. Here, we investigated the combinatory effect of paclitaxel and metformin on the cell survival in SK-MEL-28 melanoma cell line. Our study shows that the combination of paclitaxel and metformin has synergistic effect on cell survival and suppresses the expression of proteins involved in cancer metastasis. These findings suggest that the combination of paclitaxel and metformin can be a possible therapeutic option for treatment of melanoma.
\end{abstract}

Key words : Paclitaxel, Metformin, SK-MEL-28 melnoma cell, Cell viability, Metastasis

\section{INTRODUCTION}

Melanoma is a malignant cancer that arises from the transformation of melanocyte, the melanin-synthesizing cell in the skin. Although surgical resection is curative in its early stage, patients with metastatic melanoma show very poor prognosis. Standard cytotoxic chemotherapy gives very low response rate and immunotherapy with ipilimumab or interferon $\alpha$ shows somewhat improved responses in approximately $10 \%$ of metastatic melanoma patients (Hodi et al., 2010). More recently, based on the fact that about half of metastatic melanoma patients harbor
BRAF V600E mutation, small-molecule inhibitors such as vemurafenib and trametinib targeting this driver mutation or its downstream regulatory factor in extracellular signalregulated kinase $(E R K) / m i t o g e n-a c t i v a t e d$ protein kinase (MAPK) pathway have been developed and approved worldwide (Ranchon et al., 2015). Unfortunately, treatments of chemotherapeutic or molecular targeted drugs as monotherapy exhibit only transient responses due to development of drug resistance which results in recurrence and further progression of tumor (Nazarian et al., 2010; Villanueva et al., 2010).

Metformin is a biguanide derivative that has been wide-

Manuscript received May 14, 2019, Received in revised form May 27, 2019, Accepted June 8, 2019

${ }^{\dagger}$ Corresponding Author : Youngki Lee, Dept. of Histology, Jeju National University School of Medicine, Jeju 63243, Korea. Tel: +82-64-754-3826, Fax: +82-64-702-2687, E-mail: yklee38@jejunu.ac.kr

This is an Open Access article distributed under the terms of the Creative Commons Attribution Non-Commercial License (http:// creative-commons.org/licenses/by-nc/3.0) which permits unrestricted non-commercial use, distribution, and reproduction in any medium, provided the original work is properly cited. 
ly used as a first-line therapeutic drug for type II diabetes mellitus for over 50 years. Metformin decreases blood glucose levels by inhibiting gluconeogenesis in liver and increasing uptake and utilization of glucose by skeletal muscle (Shaw et al., 2005). It also proved to be welltolerable drug with low cost for the treatment of diabetic patients. During last decade, several studies suggest that treatment of metformin in diabetic patients lowers cancer risk and reduces cancer incidence (Donadon et al., 2010; Kong et al., 2015; Tseng, 2018). Preclinical studies revealed that metformin inhibits cell proliferation and tumor growth in various cancer cell lines including melanoma both in vitro and in vivo (Cerezo et al., 2013; Griss et al., 2015). Clinical trials also showed promising results, in which metformin treatment in non-diabetic patients with various cancers decreases the expression of $\mathrm{Ki}-67$, a marker of cell proliferation (Niraula et al., 2012; Joshua et al., 2014; Schuler et al., 2015). In addition, metformin has been reported to inhibit cell invasion and metastasis in many cancer cells, including melanoma cells (Cerezo et al., 2013; He et al., 2018).

The molecular mechanisms underlying antitumor effect of metformin have been demonstrated but revealed as a much more complex nature (Vancura et al., 2018). The most well-known effect of metformin is the inhibition of complex I in the mitochondrial electron transport chain, which leads to increasing the intracellular AMP/ATP ratio. The high AMP/ATP ratio in turn activates adenosine monophosphate activated protein kinase (AMPK), a heterotrimeric serine/threonine protein kinase which regulates the multiple signaling pathways involved in cancer cell proliferation, including the suppression of mammalian target of rapamycin (mTOR) pathway (Griss et al., 2015). Metformin-mediated AMPK activation and mTOR inhibition suppress cell proliferation through reducing phosphorylation of its major downstream targets, the $70 \mathrm{kDa}$ ribosomal protein kinase S6 (p70S6K) and eukaryotic initiation factor 4E-binding protein1 (4E-BP1) (Shaw et al.,
2005).

Paclitaxel (Taxol) is a frontline chemotherapeutic drug with a strong antitumor activity and has been used clinically for many years as a monotherapy or combination with other anticancer agents to treat a number of types of cancer including melanoma (Kottschade et al., 2011). Binding of paclitaxel to $\beta$-tubulin stabilizes the microtubule polymer and protects it from disassembly, which leads to immediate cell cycle arrest at the G2/M phase, followed by apoptotic cell death (Ganesh et al., 2007). However, the response rate of paclitaxel monotherapy is very low with $10 \%-15 \%$ and serious side effects plus drug resistance are significant clinical problems to the application of this drug in melanoma (Hersh et al., 2010). Several studies revealed that resistance to paclitaxel is associated with the activation of ERK/MAPK pathway and inhibition of this pathway selectively potentiates the paclitaxel-induced cell death in diverse cancer (McDaid and Horwitz, 2001; Gupta et al., 2014). Considering that ERK/MAPK pathway is associated with the regulation of cell survival and proliferation and mutations of BRAF and NRAS are found in $60 \%$ and $20 \%$ in malignant melanoma respectively, activation of ERK/ MAPK pathway in response to paclitaxel could compromise the anticancer effect of this drug. Of note, several recent reports showed that paclitaxel enhances metastasis by inducing the migration and invasion of cancer cells (Volk-Draper et al., 2014; Li et al., 2016).

Our previous report revealed that metformin suppresses ERK activation (Kim et al., 2018), which provides a rational molecular basis for the combination therapy of metformin and paclitaxel. The aims of this study were to determine the combined effect of metformin and paclitaxel on cell survival, and to explore the effect of combination of paclitaxel and metformin on metastasis by monitoring the regulation of proteins involved in epithelial-mesenchymal transition (EMT) in melanoma cell line SK-MEL28. Here, we show that the combination of paclitaxel and metformin has synergistic effect on cell survival and sup- 
presses the expression of proteins implicated in cancer metastasis.

\section{MATERIALS AND METHODS}

\section{Reagents and cell culture}

The human melanoma cancer cell line SK-MEL-28 was purchased from Korean Cell Line Bank (Seoul, Korea). The cells were cultured in Dulbecco's modified Eagle's medium (DMEM) supplemented with 10\% (vol/vol) heat inactivated fetal bovine serum (Gibco BRL) and 1\% streptomycin/penicillin at $37^{\circ} \mathrm{C}$ in a humidified atmosphere consisting of $5 \% \mathrm{CO}_{2}$ and $95 \%$ air. Cells were maintained mycoplasma free by treating $5 \mu \mathrm{g} / \mathrm{mL}$ of Plasmocin (InvivoGen). Paclitaxel was obtained from Sigma-Aldrich. The compound was initially dissolved in dimethyl sulfoxide (DMSO, Sigma-Aldrich) to a concentration of $1 \mathrm{mM}$ and further diluted in DMEM media. Metformin (also known as 1,1-dimethylbiguanide hydrochloride) was purchased from Sigma-Aldrich and dissolved in DMEM media to a working concentration of $100 \mathrm{mM}$.

\section{Cell viability assay}

MTT assay was applied to measure cell viability as described previously (Lee et al., 2017). Briefly, cells were harvested and seeded in 24-well plates at a concentration of $5 \times 10^{4}$ cells/well for $24 \mathrm{hr}$. Then, cells were treated with increasing concentrations of paclitaxel $(2-10 \mathrm{nM})$, metformin $(0.5-2.5 \mathrm{mM})$, their combinations or vehicle control for $72 \mathrm{hr}$. Experiments were performed in triplicate, each conducted in quadruplicate. The $\mathrm{IC}_{50}$ values (concentrations of drugs resulting in 50\% decrease in cell viability relative to controls), combination index (CI) and drug reduction index (DRI) were calculated using CompuSyn software (ComboSyn Inc). The CI value is a quantitative measure of the degree of drugs interaction. According to the recommendation of Chou-Talalay (Chou \& Talalay, 1981), $\mathrm{CI}<1$ indicates synergistic effects of drugs; $\mathrm{CI}=1$ indicates additive effect; $\mathrm{CI}>1$ indicates antagonism. DRI denotes how many folds of dose reduction are allowed for each drug due to synergism as compared to the dose of each drug alone.

\section{Western blotting}

Western blotting assays were carried out as previously described (Lee et al., 2017). Primary antibodies included pERK1/2 (Tyr204), ERK1/2, cyclin D1, N-cadherin, secreted protein acidic and rich in cysteine (SPARC), integrin $\alpha \mathrm{V}$, integrin $\beta 3$, fibronectin, GAPDH, $\beta$-actin (all from Santa Cruz Biotechnology), and p4E-BP1 (Ser65), 4EBP1, pS6 (Ser240/244), pS6 (Ser235/236), S6, pAMPKa (Tyr172), AMPKa1/2, pp38 (Thr180/Tyr182), p38 (all from Cell Signaling Technology, MA, USA). Following incubation with secondary antibodies conjugated to horseradish peroxidase (Cell Signaling), immunoreactivity was detected with enhanced chemiluminescence method (Santa Cruz Biotechnology).

\section{Colony formation assay}

Cells were plated in 6-well culture dishes at a density of 600 cells per well. After $24 \mathrm{hr}$, cells were treated with paclitaxel, metformin and their combination. Every three days, medium was changed with fresh medium containing the corresponding concentration of the drugs. Following 15day treatment, cell colonies were washed with cold PBS and then fixed with ice-cold $100 \%$ methanol. Cells were stained with $0.1 \%$ crystal violet in $20 \%$ methanol for $10 \mathrm{~min}$ and pictures were taken with a digital camera (Olympus).

\section{RESULTS}

1. Effect of paclitaxel and metformin on the activity of signaling pathways

To determine whether single agent paclitaxel and metformin could affect the activity of cell signaling pathways in SK-MEL-28 melanoma cells, we first screened the al- 
terations of main downstream effector proteins of mTOR, ERK/MAPK and p38 MAPK pathways following treatment of paclitaxel and metformin for $24 \mathrm{hr}$. As shown in Fig. 1, metformin inhibited the levels of pERK, p4E-BP1, pS6 (Ser235/236), pS6 (Ser240/244), pp38 and cyclin D1 in a dose-dependent manner, and increased the phosphorylation of AMPK. On the other hand, paclitaxel slightly increased the levels of pERK, p4E-BP1 and pp38, and it marginally decreased the phosphorylation AMPK. Paclita-

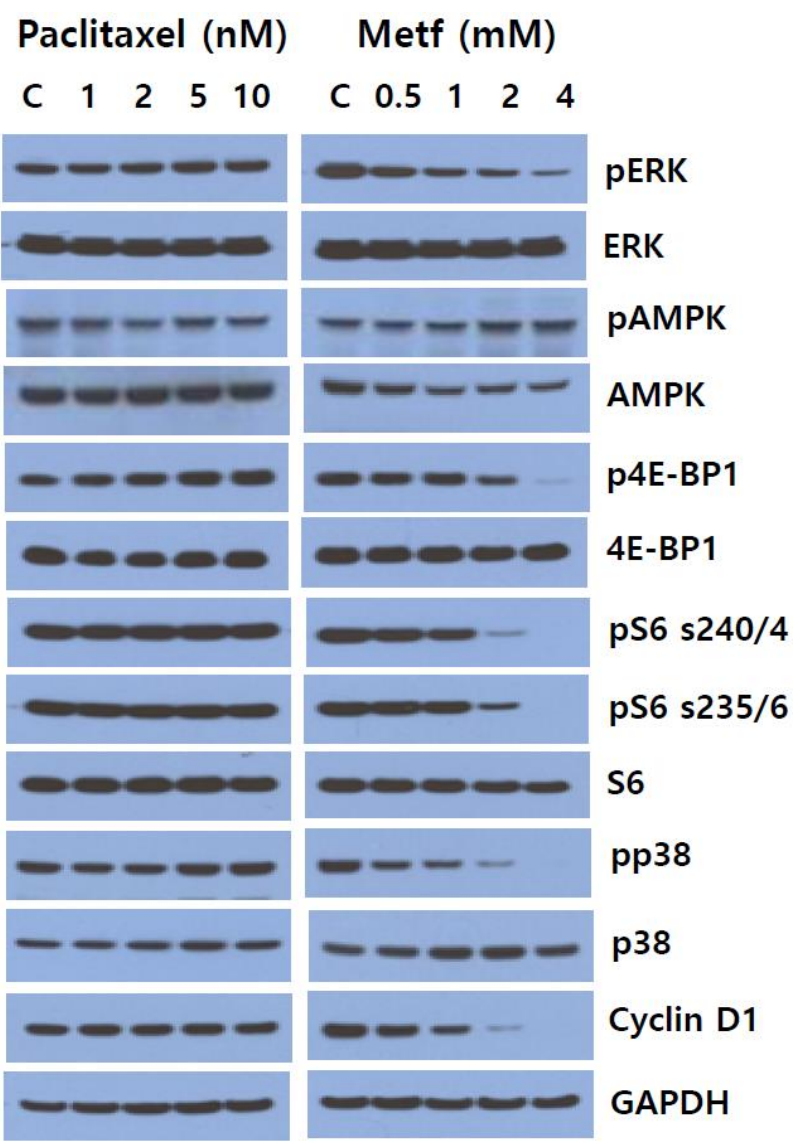

Fig. 1. Western blot analysis for downstream effector proteins involved in cell signaling pathways. SK-MEL-28 melanoma cells were treated with increasing doses of paclitaxel $(1-10 \mathrm{nM})$ or metformin (0.5-4 mM) for $24 \mathrm{hr}$. Phosphorylation was determined with antibodies against specific phospho-proteins compared to their total proteins. Glyceraldehyde-3-phosphate dehydrogenase (GAPDH) was used as a loading control. xel had no obvious effect on pS6 (Ser235/236), pS6 (Ser 240/244) and cyclin D1. These results show that metformin exerts its effect in the direction of inhibiting cell signaling pathways implicated in cell survival and proliferation whereas paclitaxel plays its effect toward activation of those signaling pathways.

2. Effect of paclitaxel, metformin and their combination on melanoma cell suvival

To evaluate the effect of paclitaxel, metformin or their combination on cell viability, SK-MEL-28 melanoma cells were treated with varying concentrations of drug as single agent or their combination for $72 \mathrm{hr}$, and cell viability was analyzed using MTT assay. As anticipated, relative cell viability was decreased following treatment of paclitaxel or metformin in a dose-dependent manner. $\mathrm{IC}_{50}$ values (concentrations of drugs leading to $50 \%$ decrease in cell viability relative to controls) for paclitaxel and metformin were $12.8 \mathrm{nM}$ and $3.1 \mathrm{mM}$, respectively. Combination of two drugs led to a greater inhibition of cell viability than those of paclitaxel or metformin alone (Fig. 2A). To quantify the response of melanoma cells to the combination of paclitaxel and metformin, we combined two drugs in a constant ratio to each other and measured CI and DRI using CompuSyn software. The CI values ranged from 0.8 (at the combination of $10 \mathrm{nM}$ paclitaxel and $2.5 \mathrm{mM}$ metformin) to 0.49 (at the combination of $4 \mathrm{nM}$ paclitaxel and $1 \mathrm{mM}$ metformin) and $\mathrm{CI}$ value at $\mathrm{ED}_{50}$ was 0.56 indicating synergism according to the method of Chou-Talalay (Chou \& Talalay, 1981, Fig. 2B). The DRI values were always above 1 at any combination of two drugs (Fig. 2C).

Next, to explore the mechanisms underlying the synergistic growth inhibitory effect between paclitaxel and metformin, we characterized the effect of this drug combination on downstream regulatory proteins of cell signaling pathways involved in cell survival and proliferation using Western blot analysis. After $24 \mathrm{hr}$ of treatment, the combi- 
(A)

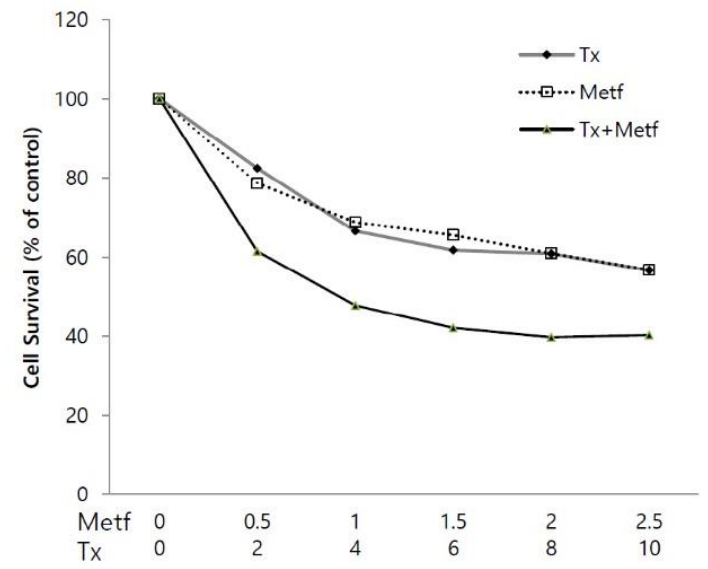

(C)

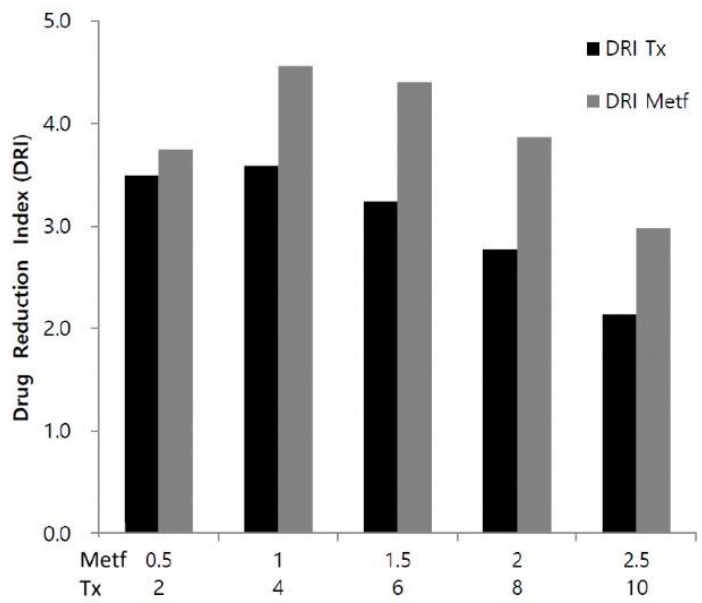

(B)

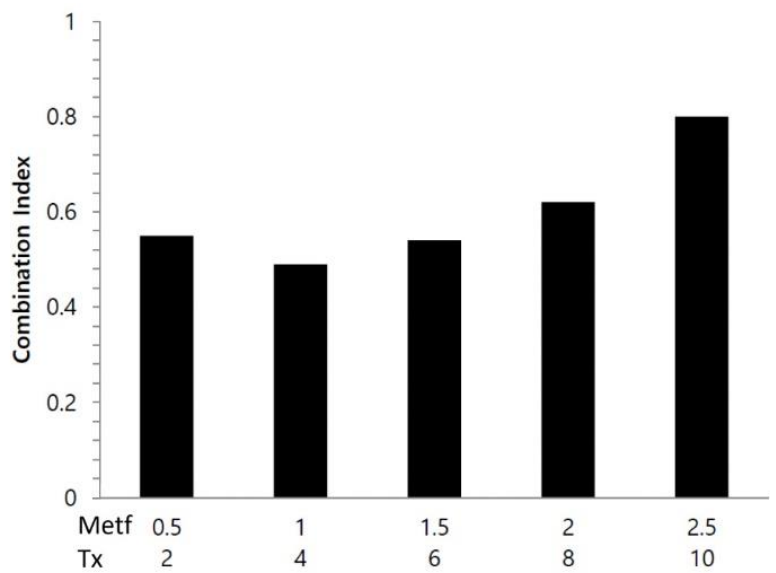

(D)

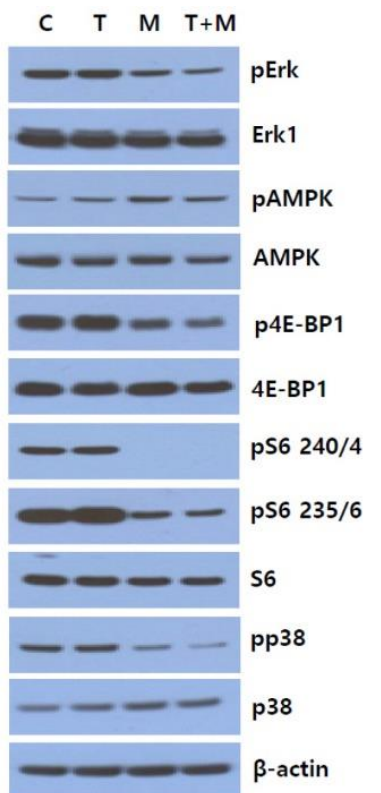

Fig. 2. Combination of paclitaxel and metformin has synergistic effect on cell viability in SK-MEL-28 melanoma cells. (A) Representative growth response curves for paclitaxel, metformin and the combination in different ratios. SK-MEL-28 cells were seeded at $5 \times 10^{4}$ cells/well $(0.5 \mathrm{~mL})$ in 24 -well culture plates, incubated for $24 \mathrm{hr}$ and then treated with paclitaxel (Tx), metformin (Metf) and their combination for $72 \mathrm{hr}$. MTT assay was performed for the determination of cell viability. The viability of control cells was regarded as $100 \%$. (B) Combination index (CI) values for the various combination points of paclitaxel and metformin. The CI values were calculated by using CompuSyn software. (C) Drug reduction index (DRI) values of combination of paclitaxel and metformin. DRI values indicate how many folds of dose reduction are allowed for each drug due to synergism as compared to the dose of each drug alone. (D) Western blot analysis for downstream regulatory proteins of cell signaling pathways. Cells were treated with paclitaxel (T, $5 \mathrm{nM})$, metformin (M, $2 \mathrm{mM})$ and their combinations for $24 \mathrm{hr}$. The combination of both drugs caused synergistic decrease of pERK, p4E-BP1 and pp38. $\beta$-actin was used as a loading control.

nation of paclitaxel and metformin led to the enhanced suppression of ERK, 4E-BP1 and p38 phosphorylation compared to that of single agent treatment. But paclitaxel did not affect the metformin-induced suppression of $\mathrm{pS} 6$ (Serine235/236) and pS6 (Serine240/244), and did not show any significant effect on metformin-induced aci- 
vation of AMPK (Fig. 2D).

\section{Effect of paclitaxel and metformin on the expres-} sion of proteins involved in EMT

Since recent reports suggest that metformin blocks metastasis development and paclitaxel enhances metastasis by inducing the migration and invasion of cancer cells (Cerezo et al., 2013; Volk-Draper et al., 2014), we determine by Western blot assay whether paclitaxel, metformin or their combination affect the expression of proteins involved in EMT. Metformin decreased the expression of SPARC and fibronectin in a dose-dependent manner, and levels of integrin $\beta 3$, integrin $\alpha \mathrm{V}$ and $\mathrm{N}$-cadherin were also decreased. In contrast, paclitaxel increased the levels of fibronectin and integrin $\beta 3$, while it did not significantly affect levels of SPARC, integrin $\alpha \mathrm{V}$ and N-cadherin (Fig. 3). Next, we explored changes in the levels of those EMT marker proteins to determine the effect of paclitaxel and metformin combination. Our results showed that paclitaxel potentiated the metformin-induced inhibition of SPARC and fibronectin while there were no obvious alteration in the levels of $\mathrm{N}$-cadherin, integrin $\alpha \mathrm{V}$ and integrin $\beta 3$.
4. Metformin potentiates the inhibition of paclitaxelinduced colony formation

In the present study, we revealed that metformin synergistically inhibits the melanomal cell growth induced by paclitaxel. To extend these results into long-term effect of the combination treatment, we tried colony formation assay by culturing SK-MEL-28 melanoma cells for 15 days. As shown in Fig. 4, paclitaxel or metformin as a single agent led to a partial inhibition of colony formation, whereas the combination of both drugs potentiated the inhibitory effect on the formation and growth of cell colonies as compared to either agent alone. These results further support the synergistic growth inhibitory effect of paclitaxel and metformin in cell survival assay.

\section{DISCUSSION}

The new therapeutic approach is important to manage the metastatic melanoma which is resistant to existing chemotherapies. Although the recently developed molecular targeted drugs like dabrafenib and trametinib show very high response rate (about $60 \%$ ) for patients with V600

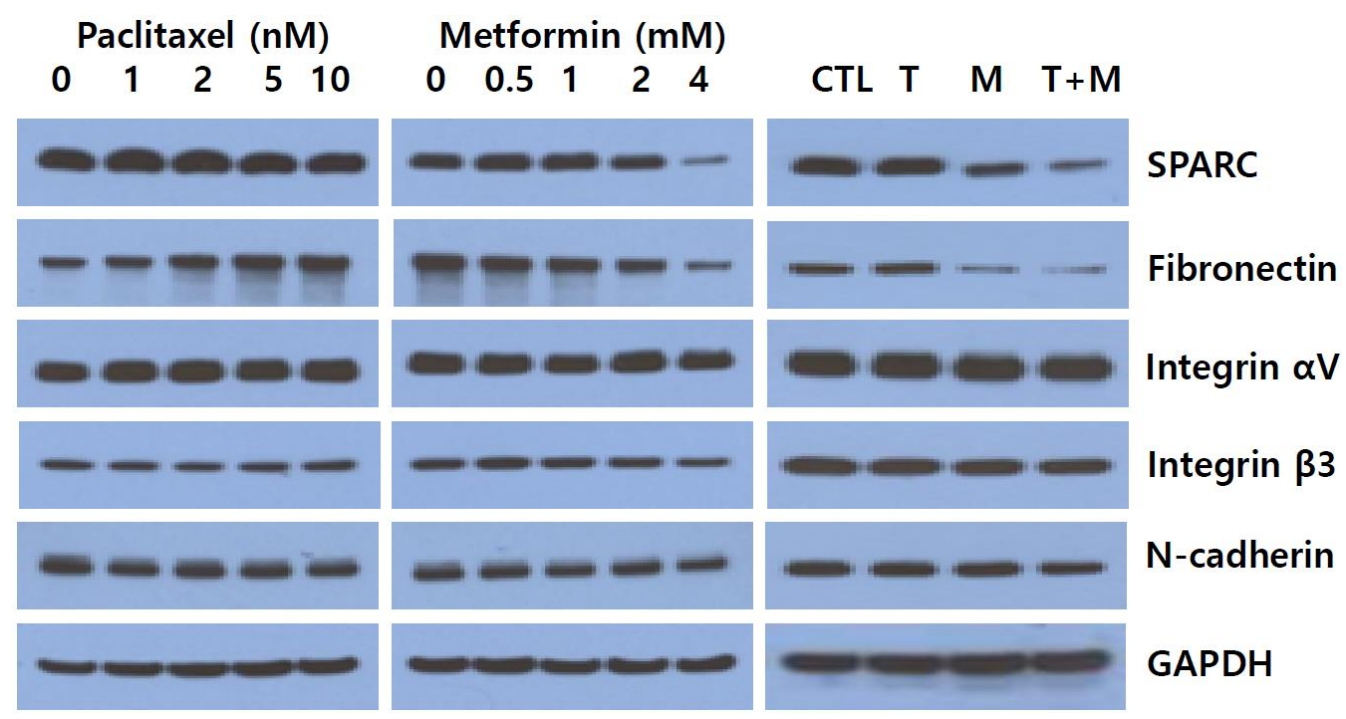

Fig. 3. Western blot analyses for EMT markers in SK-MEL-28 melanoma cells. Cells were treated with increasing doses of paclitaxel (1-10 $\mathrm{nM})$ and metfromin $(0.5-4 \mathrm{mM})$ and their combination (5 $\mathrm{nM}$ paclitaxel and $2 \mathrm{mM}$ metformin) for $24 \mathrm{hr}$. GAPDH was used as a loading control. 


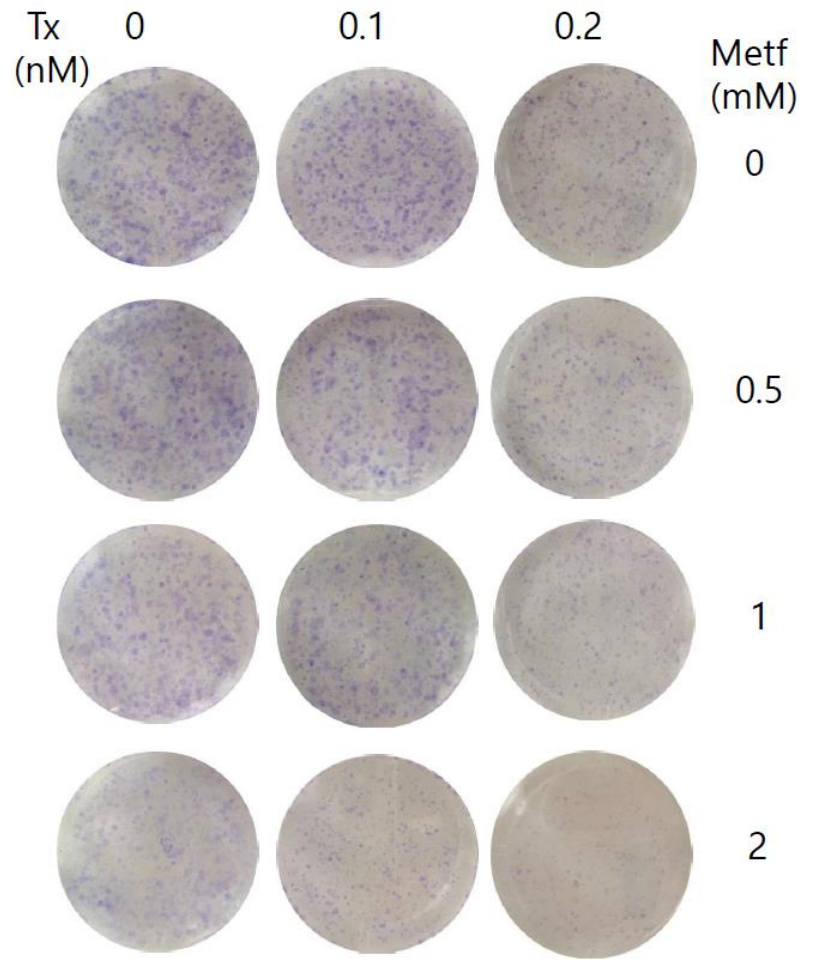

Fig. 4. Effect of paclitaxel and metformin combination on colony formation in SK-MEL-28 melanoma cells. Cells were seeded in 6-well plates at a density of 600 cells per well. At $24 \mathrm{hr}$ after plating, cells were treated with indicated concentrations of paclitaxel and metformin. Following 15-day treatment, cell colonies were stained using crystal violet dye and pictures were taken with a digital camera. Tx, paclitaxel; Metf, metformin.

mutation of BRAF gene, most responses are unfortunately transient due to drug resistance and serious toxicity (Nazarian et al., 2010). Paclitaxel is a clinically active agent for treatment of a wide range of cancers including melanoma (Kottschade et al., 2011). In addition to its well-known effects on microtubule dynamics, several studies have reported activation of components of ERK/MAPK pathway in response to paclitaxel treatment (Xu et al., 2009). Activation of ERK/MAPK pathway after paclitaxel treatment may diminish its antitumor activity, since this signaling pathway is associated with cell survival and proliferation. The antidiabetic drug metformin proved to be welltolerable drug with safety profile and low cost. Metformin as monotherapy or combination therapy inhibits the growth and proliferation of melanoma cell in vitro and in xenograft model (Niehr et al., 2011; Vujic et al., 2014). Our previous reports showed that metformin exerts its antitumor activity via the suppression of ERK phosphorylation as well as mTOR signaling pathway (Lee et al., 2017; Kim et al., 2018). We, therefore, hypothesized that the combination of paclitaxel and metformin might be an effective strategy for inhibition of cell survival and proliferation in melanoma.

The present study demonstrated the synergistic inhibition of cell survival following combination therapy with paclitaxel and metformin in human SK-MEL-28 melanoma cell line. Metformin treatment decreased levels of pS6 (Ser235/6 and Ser240/4) and p4E-BP1, two main downstream targets of mTOR signaling pathway. Metformin also led to suppression of ERK and p38 phosphorylation. On the other hand, paclitaxel induced the phosphorylation of ERK and 4E-BP1. The combination of paclitaxel and metformin synergistically reduced the levels of pERK, p4E-BP1 and pp38 MAPK as compared to the results from treatment of paclitaxel or metformin alone. These results suggest that metformin may suppress the paclitaxel-induced and/or constitutive activation of ERK, 4E-BP1 and p38, and are in agreement with a report showing that combination of paclitaxel with MAPK kinase inhibitor gives additive effect only in cell lines exhibiting paclitaxel-induced ERK activation, and antagonism in cells with low ERK activity (McDaid \& Horwitz, 2001). Of note is that metformin induced the phosphorylation of AMPK, whereas paclitaxel reduced the level of pAMPK. Interestingly, the combination of paclitaxel and metformin resulted in sustained activation of AMPK, indicating that paclitaxel did not seem to influence significantly the effect of metformin on AMPK activation.

Another notable and unexpected new finding in this study is that metformin reduced the phosphorylated form of p38 and the combination of paclitaxel and metformin 
led to almost complete suppression of p38 activity. p38 MAPK plays dual role as a regulator of cell death, and it can either mediate cell survival or cell death depending on not only the type of stimulus but also in a cell type specific manner (Koul et al., 2013). In addition, most carcinoma cells have shown that the activity of ERK/MAPK and p38 MAPK pathways appears to be mutually exclusive; high level of p38 activity inhibits ERK activity through negative feedback and prevents tumorigenesis (Aguirre-Ghiso et al., 2004). In melanoma, however, both pathways are simultaneously activated, because the negative loop from p38 to ERK is lost and melanoma cells are insensitive to ERK inhibition by p38. This high activity of p38 and ERK in melanoma is correlated with cell proliferation and migration in vivo (Estrada et al., 2008). Therefore, simultaneous inhibition of ERK and p38 activities could be more effective in blocking melanoma cell growth than suppression of each kinase individually and our present results from metformin alone or combination treatment with paclitaxel proved to meet these requirements.

Several recent studies indicate that metformin displays anti-invasion and anti-metastatic properties independently of its effect on cell survival, and the inhibition of metastatic activity is correlated with modulation of expression of proteins involved in EMT such as SPARC, fibronectin and $\mathrm{N}$-cadherin in melanoma cells (Cerezo et al., 2013; He et al., 2018). On the contrary, there is accumulating evidence that paclitaxel promotes metastasis especially in breast cancer while inhibiting the growth of primary tumors (Volk-Draper et al., 2014; Li et al., 2016). So, we wonder whether paclitaxel might compromise the anti-metastatic effect of metformin in melanoma cell. Our results showed that the combination of paclitaxel and metformin synergistically reduces the level of SPARC and fibronectin. Further studies are required to elucidate the effect of combination of paclitaxel and metformin on cell invasion and migration, the important features found in cancer metastasis.

Overall, the present study shows that metformin alone or the combination of paclitaxel and metformin suppresses the activities of S6/4E-BP1, ERK and p38, pivotal effector proteins in mTOR, ERK/MAPK and p38 MAPK signaling pathways, respectively. In addition, the combination of paclitaxel and metformin synergistically inhibited melanoma cell growth and suppressed the regulatory proteins associated with EMT. Further studies are needed to reveal the in vivo effect of our combination strategy. To our knowledge, this study is the first report to show synergistic anti-tumor effect between paclitaxel and metformin in melanoma cell line and provides evidence that the combination of paclitaxel and metformin can be a therapeutic option for the treatment of melanoma.

\section{ACKOWLEDGEMENTS}

This research was supported by the 2018 scientific promotion program funded by Jeju National University.

\section{REFERENCES}

Aguirre-Ghiso JA, Ossowski L, Rosenbaum SK (2004) Green fluorescent protein tagging of extracellular signal-regulated kinase and p38 pathways reveals novel dynamics of pathway activation during primary and metastatic growth. Cancer Res 64:7336-7345.

Cerezo M, Tichet M, Abbe P, Ohanna M, Lehraiki A, Rouaud F, Allegra M, Giacchero D, Bahadoran P, Bertolotto C, Tartare-Deckert S, Ballotti R, Rocchi S (2013) Metformin blocks melanoma invasion and metastasis development in AMPK/p53-dependent manner. Mol Cancer Ther 12:1605-1615.

Chou TC, Talalay P (1981) Generalized equations for the analysis of inhibitions of Michaelis-Menten and higher-order kinetic systems with two or more mutually exclusive and nonexclusive inhibitors. Eur J Biochem 115:207-216.

Donadon V, Balbi M, Mas MD, Casarin P, Zanette G (2010) 
Metformin and reduced risk of hepatocellular carcinoma in diabetic patients with chronic liver disease. Liver Int 30:750-758.

Estrada Y, Dong J, Ossowski L (2008) Positive crosstalk between ERK and p38 in melanoma stimulates migration and in vivo proliferation. Pigment Cell Melanoma Res 22:66-76.

Ganesh T, Yang C, Norris A, Glass T, Bane S, Ravindra R, Banerjee A, Metaferia B, Thomas SL, Giannakakou P, Alcarez AA, Lakdawala AS, Snyder JP, Kingston DG (2007) Evaluation of the tubulin-bound paclitaxel conformation: Synthesis, biology, and SAR studies of C-4 to $\mathrm{C}-3$ ' bridged paclitaxel analogues. J Med Chem 50:713-725.

Griss T, Vincent EE, Egnatchik R, Chen J, Ma EH, Faubert B, Violet B, DeBerardinis RJ, Jones RG (2015) Metformin antagonizes cancer cell proliferation by suppressing mitochondrial-dependent biosynthesis. PLOS Biol 13:e1002309.

Gupta A, Love S, Schuh A, Shanyinde M, Larkin JM, Plummer R, Nathan PD, Danson S, Ottensmeier CH, Lorigan P, Collins L, Wise A, Asher R, Lisle R, Middleton MR (2014) DOC-MEK: A double-blind randomized phase II trial of docetaxel with or without selumetinib in wild-type BRAF advanced melanoma. Ann Oncol 25:968-974.

He Y, Tan X, Hu H, Wang Q, Hu X, Cai X, Guan Y, Chen B, Jing X (2018) Metformin inhibits the migration and invasion of esophageal squamous cell carcinoma cells by downregulating the protein kinase B signaling pathway. Oncol Lett 15:2939-2945.

Hersh EM, O’Day SJ, Ribas A, Samlowski WE, Gordon MS, Shechter DE, Clawson AA, Gonzalez R (2010) Phase II clinical trial of nab-paclitaxel in previously treated and chemotherapy-naive patients with metastatic melanoma. Cancer 116:155-163.

Hodi FS, O’Day SJ, McDermott DF, Weber RW, Sosman JA, Haanen JB, Gonzalez R, Robert C, Schadendorf D,
Hassel JC, Akerley W, van den Eertwegh AJ, Lutzky J, Lorigan P, Vaubel JM, Linette GP, Hogg D, Ottensmeier CH, Lebbe C, Peschel C, Quirt I, Clark JI, Wolchok JD, Weber JS, Tian J, Yellin MJ, Nichol GM, Hoos A, Urba WJ (2010) Improved survival with ipilimumab in patients with metastatic melanoma. N Engl J Med 363:711-723.

Joshua AM, Zannella VE, Downes MR, Bowes B, Hersey K, Koritzinsky M, Schwab M, Hoffman U, Ewans A, van der Kwast T, Trachtenberg J, Finelli A, Fleshner N, Sweet J, Pollak M (2014) A pilot 'window of opportunity' neoadjuvant study of metformin in localised prostate cancer. Prostate Cancer Prostatic Dis 17:252258.

Kim T, Kim T, Choi S, Ko H, Park D, Lee YK (2018) Combination of BEZ235 and metformin has synergistic effect on cell viability in colorectal cancer cells. Dev Reprod 22:133-142.

Kong F, Gao F, Liu H, Chen L, Zheng R, Yu J, Li X, Liu G, Jia Y (2015) Metformin use improves the survival of diabetic combined small-cell lung cancer patients. Tumor Biol 36:8101-8106.

Kottschade LA, Suman VJ, Amatruda T 3rd, McWilliams RR, Mattar BI, Nikcevich DA, Behrens R, Fitch TR, Jaslowski AJ, Markovic SN (2011) A phase II trial of nab-paclitaxel (ABI-007) and carboplatin in patients with unresectable stage IV melanoma : A North Central Cancer Treatment Group Study, N057E(1). Cancer 117:1704-1710.

Koul HK, Pal M, Koul S (2013) Role of p38 MAP kinase signal transduction in solid tumors. Genes Cancer 4: 342-359.

Lee J, Park D, Lee YK (2017) Metformin synergistically potentiates the antitumor effects of imatinib in colorectal cancer cells. Dev Reprod 21:139-150.

Li Q, Ma Z, Liu Y, Kan X, Wang C, Su B, Li Y, Zhang Y, Wang P, Luo Y, Na D, Wang L, Zhang G, Zhu X, Wang L (2016) Low doses of paclitaxel enhance liver metas- 
tasis of breast cancer cells in the mouse model. FEBS J 283:2836-2852.

McDaid HM, Horwitz SB (2001) Selective potentiation of paclitaxel (Taxol)-induced cell death by mitogenactivated protein kinase inhibition in human cancer cell lines. Mol Pharmacology 60:290-301.

Nazarian R, Shi H, Wang Q, Kong X, Koya RC, Lee H, Chen Z, Lee MK, Attar N, Sazegar H, Chodon T, Nelson SF, McArthur G, Sosman JA, Ribas A, Lo RS. (2010) Melanomas acquire resistance to B-RAF(V600E) inhibition by RTK or N-RAS upregulation. Nature 468: 973-977.

Niehr F, von Euw E, Attar N, Guo D, Matsunaga D, Sazegar H, Ng C, Glaspy JA, Recio JA, Lo RS, Mischel PS, Comin-Andix B, Ribas A (2011) Combination therapy with vemurafenib (PLX4032/RG7204) and metformin in melanoma cell lines with distinct driver mutations. J Transl Med 9:76-88.

Niraula S, Dowling RJ, Ennis M, Chang MC, Done SJ, Hood N, Escallon J, Leong WL, McCready DR, Reedijk M, Stambolic V, Goodwin PJ (2012) Metformin in early breast cancer: A prospective window of opportunity neoadjuvant study. Breast Cancer Res Treat 135: 821-830.

Ranchon F, Boespflug A, Rioufol C, Schwierta V, Thomas SL, Dalle S (2015) New treatments for cutaneous metastatic melanoma: MAPK pathway-targeted and immune based therapies. AntiCancer Agents Med Chem 15:461-467.

Schuler KM, Rambally BS, DiFurio MJ, Sampey BP, Gehrig PA, Makowski L, Bae-Jump VL (2015) Antiproliferative and metabolic effects of metformin in a preoperative window clinical trial for endometrial cancer. Cancer Med 4:161-173.
Shaw RJ, Lamia KA, Vasquez D, Koo SH, Bardeesy N, Depinho RA, Montiminy M, Cantley LC (2005) The kinase LKB1 mediates glucose homeostasis in liver and therapeutic effects of metformin. Science 310:16421646.

Tseng CH (2018) Metformin is associated with decreased skin cancer risk in Taiwanese patients with type 2 diabetes. J Am Acad Dermatol 78:694-700.

Vancura A, Bu P, Bhagwat M, Zeng J, Vancurova I (2018) Metformin as an anticancer agent. Trends Pharmacol Sci 39:867-878.

Villanueva J, Vultur A, Lee JT, Somasundaram R, Fukunaga-Kalabis M, Cipolla AK, Wubbenhorst B, Xu X, Gimotty PA, Kee D, Santiago-Walker AE, Letrero R, D'Andrea K, Pushparajan A, Hayden JE, Brown KD, Laquerre S, McArthur GA, Sosman JA, Nathanson KL, Herlyn M (2010) Acquired resistance to BRAF inhibitors mediated by a RAF kinase switch in melanoma can be overcome by cotargeting MEK and IGF-1R/ PI3K. Cancer Cell 18:683-695.

Volk-Draper L, Hall K, Griggs C, Rajput S, Kohio P, DeNardo D, Ran S (2014) Paclitaxel therapy promotes breast cancer metastasis in a TLR4-dependent manner. Cancer Res 74:5421-5434.

Vujic I, Sanlorenzo M, Posch C, Esteve-Puig R, Yen AJ, Kwong A, Tsumra A, Murphy R, Rappersberger K Ortiz-Urda S (2014) Metformin and trametinib have synergistic effects on cell viability and tumor growth in NRAS mutant cancer. Oncotarget 6:969-978.

Xu R, Sato N, Yanai K, Akiyoshi T, Nagai S, WadaJ, Koga K, Mibu R, Nakamura M, Katano M (2009) Enhancement of paclitaxel-induced apoptosis by inhibition of mitogen-activated protein kinase pathway in colon cancer cells. Anticancer Res 29:261-270. 